\title{
Moção de Apoio à Revisão dos Parâmetros de Classificação das Revistas na Área de Saúde Coletiva da Capes
}

São Paulo, 20 de abril de 2011

À Presidente do V Congresso Brasileiro de Ciências Sociais e Humanas em Saúde

O Fórum de Editores de Revistas da Área de Ciências Sociais e Humanas em Saúde, reunido em 18/o4/2011, durante o V Congresso Brasileiro de Ciências Sociais e Humanas em Saúde, com a participação expressiva de editores das diversas revistas do campo da Saúde Coletiva e autores, vem solicitar, pela importância dos assuntos discutidos, a inclusão na agenda da ABRASCO do debate das questões que seguem e o encaminhamento deste documento a Área de Saúde Coletiva da CAPES.

Os participantes concluíram pela urgente necessidade de revisão dos parâmetros de classificação das revistas na área de saúde coletiva da CAPES.

Reiteradamente temos presenciado manifestações de pesquisadores, docentes, autores e editores criticando veementemente a hegemonia de abordagens biomédicas em detrimento da natureza plural, rica e interdisciplinar do campo da Saúde Coletiva, com o risco de exclusão de áreas importantes como as ciências sociais, ambientais, a saúde do trabalhador, gestão, promoção da saúde, etc.

Os participantes verificam esta hegemonia como uma ameaça de empobrecimento do campo e solicitam que sejam respeitadas e valoradas distintamente as características específicas e a diversidade do campo que inclui entre outras as ciências sociais e humanas, e que se considere a produção de critérios qualitativos de avaliação das revistas.

Avaliam que os critérios bibliométricos vêm respondendo mais à lógica de mercado com claro favorecimento dos periódicos internacionais, em detrimento de importantes esforços nacionais, como as citações por meio do SciELO.
Consideram ainda que a internacionalização não deva se limitar a versão em inglês dos artigos mantendo-se "resíduos" colonialistas, respeitando a circulação de artigos sobre localidades e especificidades geográficas ou sociais singulares.

Percebe-se ainda um distanciamento do caráter formativo de linhas editoriais, que se preocupam em estimular o debate e reflexão entre autores e leitores e, particularmente, na formação de novos autores.

O Fórum recomenda que os editores devam constituir agenda de trabalho visando garantir a multiplicidade de revistas da área, discutir a política de financiamento, promover formas de colaboração entre as novas revistas e revistas consolidadas, e estimular o ingresso de novos participantes na ABEC.

Recomenda ainda a realização de seminários conjuntos entre fórum de editores e fórum de coordenadores de pós-graduação da área.

\section{Presentes ao Forum}

\section{Cadernos de Saúde Pública}

Suely F. Deslandes

\section{Editora Hucitec}

Yara Maria de Carvalho

Interface, Comunicação, Saúde e Educação

Lilia Blima Schraiber

Physis

Kenneth Rochel de Camargo Jr

Revista Brasileira de Ciências Sociais

Mirian da Silveira Pavanelli

Revista Brasileira de Saúde Ocupacional

Eduardo Garcia

Salud Colectiva

Hugo Spinelli 
Saúde \& Transformação Social

Charles Dalcanale Tesser

Saúde e Sociedade

Cleide Lavieri Martins

\section{Demais participantes}

Aurea Ianni; Gladys Benito; Helena Ribeiro; Ivan França Junior, Mara de Andréa Gomes; Maria da Penha C. Vasconcellos; Rodolfo Vilela; e Rubens Adorno.

\section{Associaram-se ao Documento}

\section{Ciência \&Saúde Coletiva}

Maria Cecilia de Souza Minayo

Revista de Bioética

Gerson Zafalon Martins e Dora Porto

Revista de Direito Sanitário

Sueli Dallari

\section{Revista Baiana de Saúde Pública}

Lorene Louise Silva Pinto

Saúde em Debate

Paulo Amarante 